\title{
TRPV4 is associated with central rather than nephrogenic osmoregulation
}

\author{
Sylvie Janas ${ }^{1} \cdot$ François Seghers $^{2,8}$ • Olivier Schakman ${ }^{2} \cdot$ Mohammad Alsady $^{3}$. \\ Peter Deen $^{3}$ • Joris Vriens ${ }^{4}$. Fadel Tissir ${ }^{5}$. Bernd Nilius ${ }^{6}$. Johannes Loffing ${ }^{7}$. \\ Philippe Gailly $^{2}$ - Olivier Devuyst ${ }^{8}$
}

Received: 21 March 2016 /Revised: 7 June 2016 / Accepted: 9 June 2016

(C) Springer-Verlag Berlin Heidelberg 2016

\begin{abstract}
TRPV4 is a polymodal cation channel expressed in osmosensitive neurons of the hypothalamus and in the mammalian nephron. The segmental distribution and role(s) of TRPV4 in osmoregulation remain debated. We investigated the renal distribution pattern of TRPV4 and the functional consequences of its disruption in mouse models. Using qPCR on microdissected segments, immunohistochemistry, and a $L a c Z$ reporter mouse, we found that TRPV4 is abundantly expressed in the proximal tubule, the late distal convoluted tubule, and throughout the connecting tubule and collecting duct, including principal and intercalated cells. TRPV4 was undetectable in the glomeruli and thick ascending limb and weakly abundant in the early distal convoluted tubule. Metabolic studies in $\operatorname{Trp} v 4^{+/+}$and $\operatorname{Trp} v 4^{-/-}$littermates
\end{abstract}

Philippe Gailly and Olivier Devuyst co-directed the study and are cosenior authors.

Sylvie Janas and François Seghers contributed equally to this work.

Electronic supplementary material The online version of this article (doi:10.1007/s00424-016-1850-5) contains supplementary material, which is available to authorized users.

Olivier Devuyst

olivier.devuyst@uzh.ch

1 Division of Nephrology, Université catholique de Louvain Medical School, 1200 Brussels, Belgium

2 Laboratory of Cellular Physiology, Université catholique de Louvain Medical School, 1200 Brussels, Belgium

3 Department of Physiology, Radboud University Medical Center, Nijmegen, The Netherlands revealed that the lack of TRPV4 did not influence activity, food and water intake, renal function, and urinary concentration at baseline. The mice showed a similar response to furosemide, water loading and deprivation, acid loading, and dietary $\mathrm{NaCl}$ restriction. However, Trpv $4^{-/-}$mice showed a significantly lower vasopressin synthesis and release after water deprivation, with a loss of the positive correlation between plasma osmolality and plasma vasopressin levels, and a delayed water intake upon acute administration of hypertonic saline. Specific activation of TRPV4 in primary cultures of proximal tubule cells increased albumin uptake, whereas no effect of TRPV4 deletion could be observed at baseline. These data reveal that, despite its abundant expression in tubular segments, TRPV4 does not play a major
4 Laboratory of Experimental Gynaecology, Katholieke Universiteit Leuven, 3000 Leuven, Belgium

5 Institute of Neuroscience, Université catholique de Louvain Medical School, 1200 Brussels, Belgium

6 Laboratory of Ion Channel Research, Katholieke Universiteit Leuven, 3000 Leuven, Belgium

Institute of Anatomy, University of Zurich, CH-8057 Zurich, Switzerland

8 Institute of Physiology, University of Zurich, Winterthurerstrasse 190, CH-8057 Zurich, Switzerland 
role in the kidney or is efficiently compensated when deleted. Instead, TRPV4 is critical for the release of vasopressin, the sensation of thirst, and the central osmoregulation.

Keywords Osmoregulation · TRPV4 · Tubular functions . Vasopressin · Thirst

\section{Introduction}

Osmoregulation is essential for every organism. In mammals, the homeostatic regulation of body water content involves a concerted action of the brain and the kidney. While the kidney is mainly an effector handling water, the control center is in the hypothalamus, where are located the most influential set of osmosensitive neurons $[7,10]$. At the cellular level, ion channels are implicated in numerous osmotic and mechanical stimulus detection $[15,26]$. Studies based on mouse models [21, 22, 24] and human genetics [39] suggested that TRPV4 could be involved in systemic osmoregulation. However, although some evidence supported a physiological role of TRPV4 in the hypothalamic osmosensitive nuclei [11,21, 24], others showed opposite results $[12,17]$. Furthermore, the effect of TRPV4 disruption on $\mathrm{NaCl}$ and water handling by the nephron has not yet been studied.

TRPV4 is a cation channel that belongs to the transient receptor potential (TRP) vanilloid subfamily [36]. TRPV4 responds to a large variety of stimuli, including osmotic cell swelling, mechanical stress, temperature, endogenous arachidonic acid metabolites, and phorbol esters [20, 27, 42, 43]. In view of its expression pattern in the brain, which includes neurons of the subfornical organ, the median preoptic area, and the organum vasculosum of the lamina terminalis $[7,11,20]$, TRPV4 is likely to play a role in osmoregulation. Indeed, these neurons are endogenously osmosensitive and project to magnocellular neurons in the supraoptic (SON) and paraventricular nuclei (PVN) of the hypothalamus $[8,9]$. Magnocellular neurons possess intrinsic osmosensitivity $[28,29]$ and synthesize arginine vasopressin (AVP); they also express TRPV4 [11]. In response to increased plasma osmolality, AVP is released from the posterior pituitary gland into the blood and binds to the AVP receptor type 2 (AVPR2) in the principal cells lining the collecting ducts of the kidney. This interaction leads to a signaling cascade causing phosphorylation and apical insertion of the water channel aquaporin-2 (AQP2), which facilitates osmotically driven water reabsorption [30]. The role of TRPV4 in central osmosensors has been studied in two distinct Trpv 4 knockout mouse models $[21,24]$. Under water deprivation, Mizuno et al. reported an exaggerated AVP secretion in Trpv $4^{-/-}$ mice, while Liedtke et al. reported blunted AVP secretion and thirst mechanism. Recently, using several hypertonic challenges, Kinsman et al. questioned TRPV4 implication in thirst sensation [17].

TRPV4 is abundantly expressed in the kidney $[2,18$, 20, 40]. However, its localization along the nephron is controversial, possibly reflecting the lack of specificity of antibodies raised against TRP channels. A first study stated that TRPV4 was restricted to tubular segments constitutively impermeable to water: thick ascending thin limb (TAL), distal convoluted tubule (DCT), and collecting ducts (CDs) [40]. Along these segments, TRPV4 was found in the basolateral side of the cells. Noteworthy is that TRPV4 was absent from nephron segments exhibiting constitutive water permeability, i.e., the proximal tubules (PTs) and descending thin limbs. A subsequent study showed that TRPV4 was restricted to connecting tubules $(\mathrm{CN})$ and $\mathrm{CDs}$ [2]. In view of these discrepant results, the physiological role of TRPV4 in the kidney remains unclear.

In order to clarify the role of TRPV4 in the kidney and in osmoregulation in general, we characterized the expression of TRPV4 in the mouse kidney by using quantitative polymerase chain reaction (qPCR) on isolated nephron segments, immunohistochemistry, and a Trpv 4 reporter mouse model. We then evaluated the functional consequences of TRPV4 disruption in terms of renal function, general behavior, and specific parameters related to the osmoregulation.

\section{Materials and methods}

\section{Animals and sampling}

Experiments were conducted on 12-week-old, male Trpv $4^{+/+}$ and $\operatorname{Trp} v 4^{-/-}$mice, generated by targeted deletion of exon 12 of the Trpv 4 gene [21]. The mice were backcrossed on a C57BL/6 background before starting the study. They were housed in a light- and temperature-controlled room with ad libitum access to tap water and standard diet (AO3, SAFE, France). Basal activity was evaluated in individual metabolic cages (Physiocage, Panlab-Bioseb, Vitrolles, France) during $48 \mathrm{~h}$ after $24 \mathrm{~h}$ of habituation. Overnight urine collections were obtained in individual metabolic cages, after appropriate training. Blood was collected by venous puncture or decapitation (for vasopressin measurement), and plasma was stored at $-20{ }^{\circ} \mathrm{C}$. Tissue samples were obtained after anesthesia with Sevoflurane (Abbott, Ottignies, Belgium) and were immediately processed for fixation and RNA/protein extraction. All protocols complied with the National Research Council Guide for the Care and Use of Laboratory Animals and were approved by the local Ethics Committee. 


\section{Investigation of renal function}

Mice were placed in metabolic cages to assess diuresis and renal handling of ions at baseline and during the following protocols. The urinary concentrating ability was tested after 24-h water deprivation. The capacity to excrete a water load was tested after intraperitoneal (IP) injection of sterile water (100 $\mu \mathrm{L} / \mathrm{g})$ [1]. Parameters were also obtained after administration of a single dose of furosemide $(10 \mathrm{mg} / \mathrm{kg}, \mathrm{IP})$ or $\mathrm{NaCl}$ solution $\left(0.5 \mathrm{M}, 0.8 \mathrm{~mL} / 20 \mathrm{~g}\right.$, IP). The effect of $\mathrm{Na}^{+}$-depleted diet was investigated in Trpv $4^{-1-}$ mice receiving deionized water ad libitum and a standard diet $(1 \% \mathrm{NaCl})$ followed by a $0.01 \% \mathrm{NaCl}$ diet for 17 days.

\section{Analytic procedures}

Sodium, potassium, and chloride values were determined using a Kodak Ektachem DT60 II Analyzer (Johnson \& Johnson, New Brunswick, NJ, USA). Other electrolytes, creatinine, and urea were measured on a Synchron CX5 analyzer (Beckman Coulter, Fullerton, CA, USA). Osmolality was measured on a Fiske osmometer (Needham Heights, MA, USA). Plasma AVP levels were measured using EIA (Peninsula Laboratories, San Carlos, CA).

\section{Microdissection of individual nephron segments and primary culture}

Male $\operatorname{Tr} p v 4^{+/+}$and $\operatorname{Tr} p v 4^{-/-}$mice were decapitated and the kidneys were removed and decapsulated. The dissection was done as described previously [31]. Mouse proximal tubule cell (mPTC) culture and fluorescein isothiocyanate (FITC)-labeled albumin uptake assays were conducted as described previously [38].

\section{Calcium measurement}

mPTCs were incubated for $30 \mathrm{~min}$ at room temperature with $5 \mu \mathrm{M}$ Fura2-AM (Calbiochem, Camarillo, CA, USA), then washed for $1 \mathrm{~h}$ in Krebs-HEPES buffer and mounted in the same medium on a Zeiss Axiovert $200 \mathrm{M}$ inverted microscope (Zeiss Belgium, Zaventem, Belgium). Intracellular calcium $\left(\left[\mathrm{Ca}^{2+}\right]_{\mathrm{i}}\right)$ in individual cells was measured using alternative excitation of Fura-2/AM $(0.5 \mathrm{~Hz})$ at 340 and $380 \mathrm{~nm}$ using a Lambda DG-4 Ultra High Speed Wavelength Switcher (Sutter Instrument, Novato, CA, USA). Images were acquired with a Zeiss Axiocam camera coupled to a 510-nm emission filter and analyzed with Axiovision software.

\section{Antibodies}

The antibodies used for Western blotting and immunostaining are listed in Supplementary Material 1: Table 1.

\section{Western blotting}

Extraction and immunoblotting of kidney samples were performed as described previously [16]. Normalization was obtained after membrane stripping and reprobing.

\section{Immunostaining}

Mice were anesthetized with ketamine/xylazine (IP) and perfused through the left ventricle with phosphate-buffered saline (PBS) followed by paraformaldehyde-lysine-periodate fixative. Five-micrometer-thick cryosections (TRPV4) or sections from paraffin-embedded tissue blocks (AQP2, pAQP2, and NOS1) were incubated overnight at $4{ }^{\circ} \mathrm{C}$ with primary antibodies. Binding sites were revealed by $\mathrm{Cy} 3$-conjugated goat a

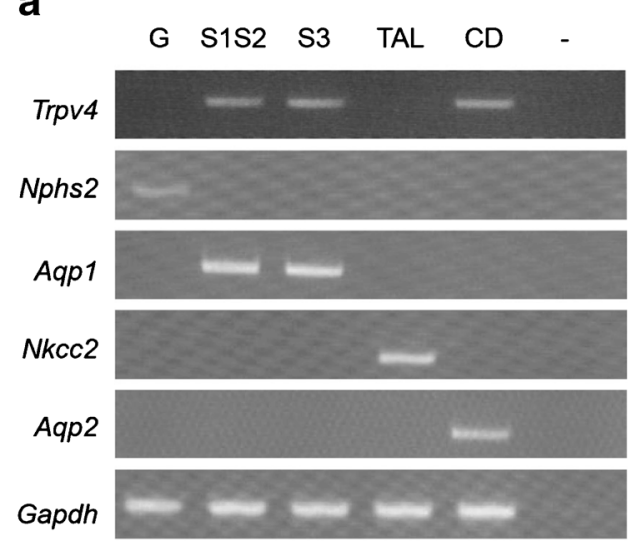

Fig. 1 Differential expression of Trpv4 in microdissected nephron segments from mouse kidney. a RT-PCR of Trpv4 mRNA with segment-specific markers. Nphs2 (Podocin) is expressed in the glomeruli, Aqp1 in PT, Nkcc2 in TAL, and Aqp2 in CD. RT-PCR

b

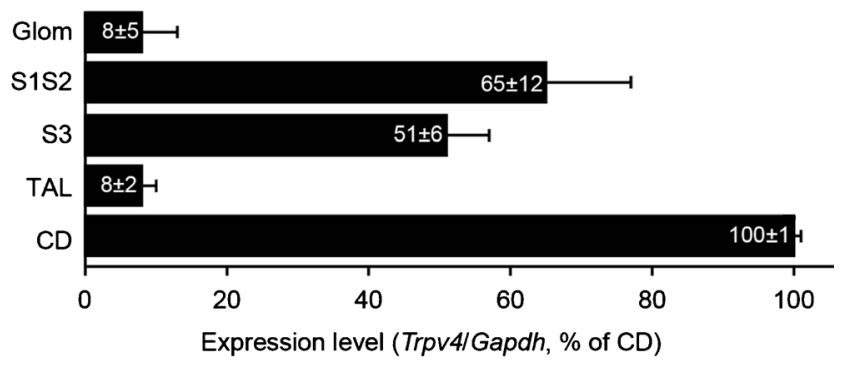

products were size-fractionated on $1.5 \%$ agarose gel. b Semiquantitative RT-PCR on microdissected segments demonstrates that Trpv4 is expressed in the pars convoluta (S1S2) and the pars recta (S3) of the PT and in the CD ( $n=5$ fractions) 
anti-rabbit $\operatorname{IgG}$ antibodies. DAPI was used to counterstain nuclei. Sections were studied by epifluorescence on a Zeiss microscope.

\section{Real-time PCR}

RNA extraction, retrotranscription, and qPCR were performed as described previously [16]. For detailed conditions and primers, see Supplementary Material 1: "Materials and Methods" and Table 2.

\section{Reporting of Trpv4 expression}

A mouse strain was generated by homologous recombination inserting a lacZ reporter gene downstream the endogenous Trpv4 promoter. Kidneys from 3-month-old heterozygous mice (Trpv $\left.4^{W t / a c Z}\right)$ were isolated, cryoprotected, and frozensectioned $(10 \mu \mathrm{M})$. For $\beta$-galactosidase activity detection, sections were fixed in $2 \%$ glutaraldehyde, washed, and stained overnight at $37{ }^{\circ} \mathrm{C}$ in PBS supplemented with $20 \mathrm{mM} \mathrm{K}_{3} \mathrm{Fe}(\mathrm{CN}), 20 \mathrm{mM} \mathrm{K}_{4} \mathrm{Fe}(\mathrm{CN})_{6}, 2 \mathrm{mM} \mathrm{MgCl}_{2}$, and $1 \mathrm{mg} / \mathrm{mL}$ Xgal. They were then washed and counterstained with Nuclear Fast Red. No staining was detected on sections from wild-type mice treated in the same conditions. For parallel immunostaining, frozen sections were fixed in methanol, then blocked and incubated with segment-specific antibodies. Binding sites were revealed using the AEC kit (Vector Laboratories).

\section{Statistical analyses}

Values are expressed as the mean \pm standard error of the mean (SEM). Statistical comparisons were assessed by ANOVA or two-tailed Student's $t$ test (GraphPad, San Diego, CA), as appropriate. $P$ values $<0.05$ were considered significant.

\section{Results}

\section{Expression and distribution of TRPV4 in mouse kidney}

We first investigated the segmental distribution of Trpv4 mRNA in mouse kidney using microdissected fractions characterized for segment-specific markers including podocin (Nphs2) for glomeruli, AQP1 (Aqp1) for PT, $\mathrm{Na}^{+}-\mathrm{K}^{+}-2 \mathrm{Cl}^{-}$ co-transporter (Nkcc2) for TAL, and AQP2 (Aqp2) for CD (Fig. 1a). The expression of Trpv4 mRNA was detected in the convoluted (S1-S2) and straight (S3) parts of the PT, as well as in the $\mathrm{CD}$, but neither in the glomerulus nor in TAL segments (Fig. 1b).

The distribution pattern of TRPV4 was established by using well-characterized antibodies that evidenced a single, specific $90-\mathrm{kDa}$ band for TRPV4 by immunoblotting as well as a distinct tubular staining in wild-type $\operatorname{Trp} v 4^{+/+}$mouse kidney (Supplementary Material 1: Fig. 1). Immunofluorescence showed that TRPV4 was widely expressed in the mouse kidney (Fig. 2). Based on co-distribution with segment-specific markers, TRPV4 was evidenced in the apical and basolateral membrane of PT cells (NaPi-2a; Fig. 2a). In the distal nephron, a slight basolateral staining for TRPV4 was detected in the first part of DCT, positive for the $\mathrm{Na}^{+}-\mathrm{Cl}^{-}$co-transporter (NCC), becoming more prominent in DCT2 (Fig. 2b) and continuing throughout the $\mathrm{CN}$ and the $\mathrm{CD}$ (AQP2; Fig. 2d). Type A intercalated cells in the CD were clearly TRPV4positive (H-ATPase; Fig. 2f). However, intercalated cells in $\mathrm{CN}$ were weakly stained (Fig. 2e). Importantly, TRPV4 immunoreactivity was absent from the TAL (NKCC2; Fig. 2c).

These results were validated using a $L a c Z$ reporter mouse, allowing to assess the segment-specific expression of Trpv4
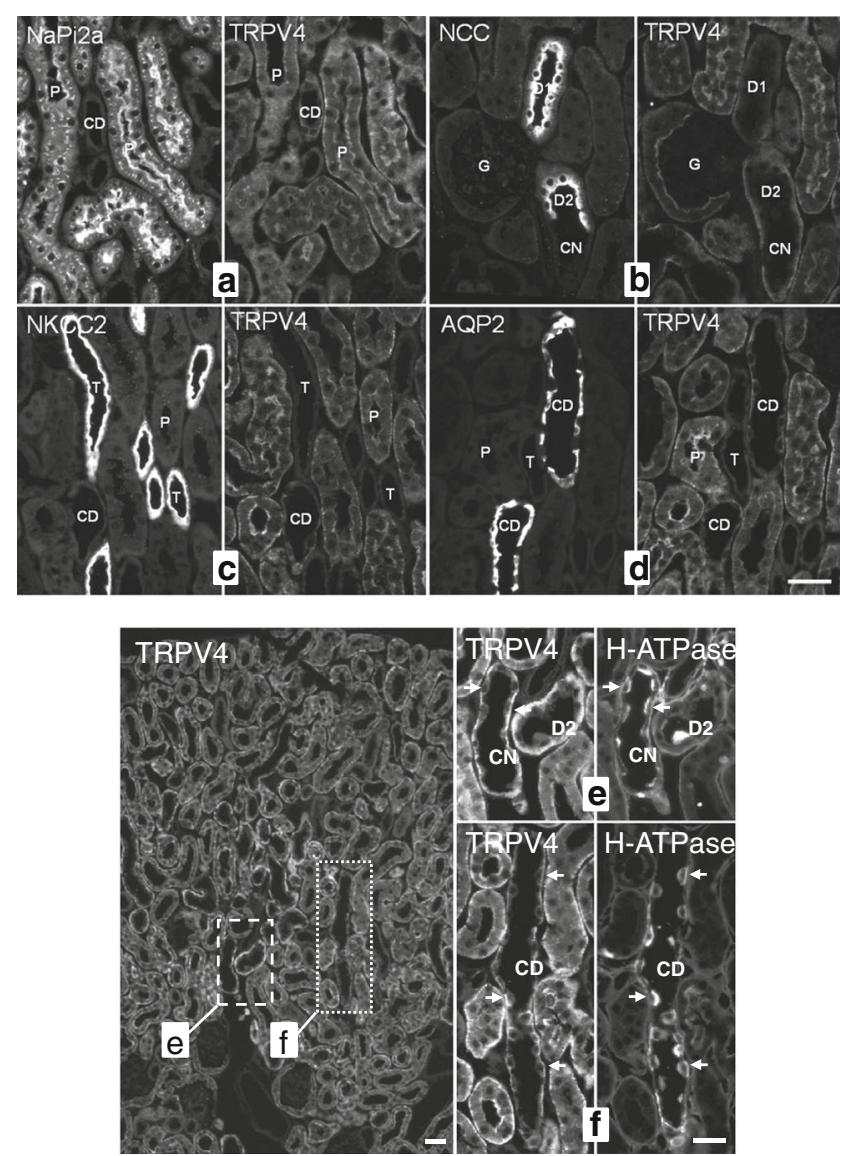

Fig. 2 Parallel staining of TRPV4 with different nephron segmentspecific markers. a Immunofluorescence staining of $\mathrm{NaPi} 2 \mathrm{a}$ and TRPV4 showing coincident staining in proximal tubules $(P)$. b Immunostaining of NCC and TRPV4 depicting co-expression in DCT1 $(D 1)$ and DCT2 (D2). TRPV4 immunoreactivity was absent in the glomerulus $(G)$. c Double staining of NKCC2 and TRPV4 showing the absence of immunoreactivity in the TAL. d Collecting ducts $(C D)$ show basolateral expression of TRPV4 and luminal AQP2 staining. e, f Details of TRPV4 staining in the distal nephron. H-ATPase-positive intercalated cells in $\mathrm{CN}$ are weakly stained $(e)$. However, intercalated cells in $\mathrm{CD}$ are clearly TRPV4-positive $(f)$. Scale bar, $50 \mu \mathrm{m}$ 
by co-staining of $\beta$-galactosidase activity (Fig. 3a-e). Confirming TRPV4 immunolocalization, the $\beta$-galactosidase activity detection reported Trpv4 expression in the PT (AQP1), the DCT (NCC), and the CD (AQP2), but not in the glomerulus and the TAL (UMOD).

\section{Functional consequences of TRPV4 disruption}

We next investigated whether the disruption of TRPV4 influences renal function in mouse. Trpv $4^{-/-}$mice had normal appearance, body weight, water intake, and food intake and showed no obvious behavioral abnormalities (testing in Physiocage) as compared to $\operatorname{Trp} v 4^{+/+}$littermates (Table 1). Similarly, there were no significant alterations in the baseline biological parameters in plasma and urine (Table 1). Notably, Trpv $4^{-/-}$mice did not exhibit urinary loss of phosphate, glucose, calcium, or low-molecular-weight (CC16) protein, pleading against a defect in PT function at baseline.

In order to test the physiological role of TRPV4 in the distal nephron, we administered a single dose of furosemide $(10 \mathrm{mg} / \mathrm{kg}$, IP) to the mice (Fig. 4). As expected, furosemide induced a strong diuretic response after $2 \mathrm{~h}$, with decreased urine osmolality and increased urinary excretion of $\mathrm{Na}^{+}, \mathrm{K}^{+}$, and $\mathrm{Ca}^{2+}$ (Fig. 4a-e). The response was similar in Trpv $4^{+/+}$ and $\operatorname{Trp} v 4^{-/-}$mice, suggesting functional integrity of the TAL and the $\mathrm{CD}$.

We then evaluated whether the effect of sodium deprivation was affected by the deletion of TRPV4 (Fig. 4f, g). Trpv 4 mice were fed a $\mathrm{Na}^{+}$-replete diet $(1 \% \mathrm{NaCl})$ at baseline, followed by a $\mathrm{Na}^{+}$-depleted $\operatorname{diet}(0.01 \% \mathrm{NaCl})$ for 17 days. The dietary change resulted in very similar variations in the urinary excretion of $\mathrm{Na}^{+}$and $\mathrm{K}^{+}$in $\operatorname{Trp} v 4^{+/+}$and $\operatorname{Trp} v 4^{-/-}$mice both in terms of time course and absolute levels during the sodium depletion test.

Because TRPV4 has also been detected in intercalated cells, we investigated whether the lack of TRPV4 could disrupt the ability to excrete ammonium during an oral acid load (Fig. 4h, i). The response to both short-term (2 days) and long-term (6 days) $\mathrm{NH}_{4} \mathrm{Cl}$ acid load showed that both the decrease in urine $\mathrm{pH}$ (Fig. 4h) and the increase in urinary ammonium excretion (Fig. 4i) were similar in wild-type and $\operatorname{Trpv} 4^{-/-}$mice. These data indicate that TRPV4 is not essential for the mineralocorticoid response or for the urinary acidification during metabolic acidosis.
Fig. 3 Segmental distribution of TRPV4 in the reporter mouse kidney. Serial sections of $\operatorname{Trp} v 4^{\text {WtlacZ }}$ kidney (Trpv4 expression is reported by betagalactosidase staining) co-stained with segment-specific markers. a Staining of Trpv4 and AQP1 showing co-expression in proximal tubules $(P)$. b Staining of Trpv4 and UMOD showing the absence of expression in the TAL (T). c Staining of Trpv4 and NCC showing co-expression in the DCT $(D)$. d Staining of Trpv4 and AQP2 showing co-expression in the CD. e Trpv 4 is not expressed in the glomerulus $(G)$. Scale bar, $50 \mu \mathrm{m}$
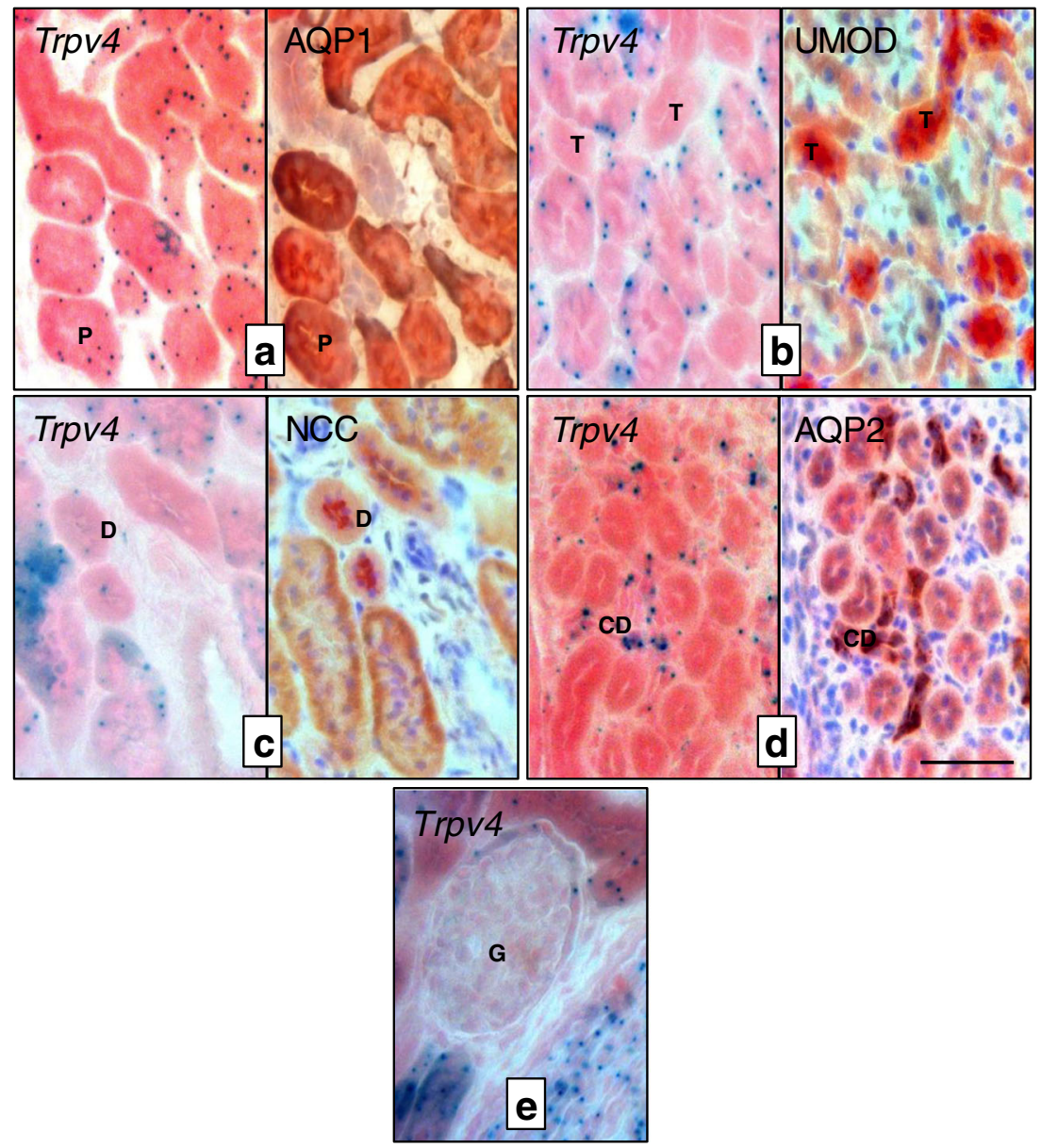
Table 1 Physical activity and biological parameters in Trpv4 mice at baseline

\begin{tabular}{|c|c|c|c|}
\hline Parameter & $\operatorname{Trp} v 4^{+/+}$ & $\operatorname{Trp} v 4^{-1-}$ & $P$ \\
\hline Body weight (g) & $21.81 \pm 0.63$ & $21.15 \pm 0.49$ & 0.42 \\
\hline Water intake (mL/g body weight) & $0.37 \pm 0.01$ & $0.39 \pm 0.03$ & 0.53 \\
\hline Food intake ( $\mathrm{g} / \mathrm{g}$ body weight) & $0.35 \pm 0.04$ & $0.38 \pm 0.03$ & 0.59 \\
\hline Activity (movements/48 h) & $24177 \pm 4988$ & $27028 \pm 3591$ & 0.65 \\
\hline Rearing (standings/48 h) & $6073 \pm 741$ & $6412 \pm 831$ & 0.77 \\
\hline \multicolumn{4}{|l|}{ Plasma } \\
\hline Osmolality $\left(\mathrm{mOsm} / \mathrm{kg} \mathrm{H}_{2} \mathrm{O}\right)$ & $321 \pm 1.95$ & $322 \pm 2.26$ & 0.68 \\
\hline Creatinine $(\mathrm{mg} / \mathrm{dL})$ & $0.11 \pm 0.01$ & $0.13 \pm 0.01$ & 0.08 \\
\hline Urea $(\mathrm{mg} / \mathrm{dL})$ & $22 \pm 0.90$ & $22 \pm 1.56$ & 0.78 \\
\hline $\mathrm{Na}^{+}(\mathrm{mM})$ & $148 \pm 0.65$ & $150 \pm 0.90$ & 0.14 \\
\hline $\mathrm{K}^{+}(\mathrm{mM})$ & $5.08 \pm 0.15$ & $4.84 \pm 0.15$ & 0.27 \\
\hline $\mathrm{Cl}^{-}(\mathrm{mM})$ & $121 \pm 1.52$ & $120 \pm 1.41$ & 0.80 \\
\hline $\mathrm{AVP}(\mathrm{ng} / \mathrm{mL})$ & $2.72 \pm 0.42$ & $3.57 \pm 0.50$ & 0.22 \\
\hline \multicolumn{4}{|l|}{ Urine } \\
\hline 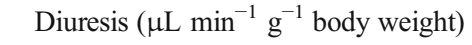 & $0.036 \pm 0.004$ & $0.033 \pm 0.004$ & 0.57 \\
\hline Osmolality $\left(\mathrm{mOsm} / \mathrm{kg} \mathrm{H}_{2} \mathrm{O}\right)$ & $2327 \pm 133$ & $2316 \pm 88$ & 0.94 \\
\hline $\mathrm{pH}$ & $6.89 \pm 0.13$ & $6.59 \pm 0.12$ & 0.07 \\
\hline $\mathrm{Na}^{+} /$creatinine (nmol/ng creatinine) & $0.29 \pm 0.02$ & $0.31 \pm 0.03$ & 0.49 \\
\hline $\mathrm{K}^{+} /$creatinine (nmol/ng creatinine) & $0.60 \pm 0.02$ & $0.58 \pm 0.03$ & 0.67 \\
\hline $\mathrm{Cl}^{-} /$creatinine (nmol/ng creatinine) & $0.37 \pm 0.01$ & $0.40 \pm 0.03$ & 0.34 \\
\hline $\mathrm{Ca}^{2+} /$ creatinine (ng/ng creatinine) & $0.11 \pm 0.01$ & $0.09 \pm 0.01$ & 0.31 \\
\hline $\mathrm{Mg}^{2+} /$ creatinine (ng/ng creatinine) & $1.20 \pm 0.11$ & $0.98 \pm 0.08$ & 0.12 \\
\hline Glucose (mg/dL) & $82.9 \pm 2.60$ & $86.6 \pm 3.64$ & 0.43 \\
\hline Phosphate (mg/dL) & $124 \pm 24.1$ & $153 \pm 21.8$ & 0.38 \\
\hline $\mathrm{CC} 16(\mu \mathrm{g} / \mathrm{L})$ & $9.44 \pm 3.71$ & $12.90 \pm 3.98$ & 0.54 \\
\hline
\end{tabular}

Data are mean $\pm \mathrm{SEM} ; n=10$ mice per group

CC16 Clara cell 16-kDa protein

\section{Effect of TRPV4 disruption on central osmoregulation}

Previous studies have demonstrated that TRPV4 is located within the forebrain lamina terminalis, a structure that is essential for both thirst and vasopressin secretion. To evaluate the central response to hyperosmotic stimuli, we challenged Trpv4 mice with an IP injection of a hyperosmotic solution $(0.5 \mathrm{M} \mathrm{NaCl}, 0.04 \mathrm{~mL} / \mathrm{g}$ body weight). Mice were single-housed, allowing the precise measurement of cumulative water intake (Physiocage testing). Under these conditions, water intake was significantly delayed in Trpv $4^{-1-}$ mice $\left(\operatorname{Trp} v 4^{-1} T_{1 / 2}=1056 \pm 245 \mathrm{~s}\right.$ versus $\operatorname{Trpv} 4^{+/+} T_{1 / 2}=672 \pm 83 \mathrm{~s}$; Fig. 5a, b), suggesting a central defect in osmoregulation.

In a second set of experiments, Trpv 4 mice were exposed to a 24-h water deprivation (Fig. 6). $\operatorname{Trp} v 4^{-/-}$mice and their control littermates had the same urine output and osmolality at baseline, with water deprivation resulting in a similar drop in urine volume (Fig. 6a) and a similar increase in urine osmolality $\left(U_{\text {Osm }}\right)$ in both groups (Fig. 6b). Of interest is that $\operatorname{Trp} v 4^{-/}$mice exhibited significantly higher levels of plasma osmolality $\left(P_{\text {Osm }}\right)$ after water deprivation (Fig. 6c) as well as a lower increase in AVP mRNA expression (Fig. 6d) and plasmatic AVP (Fig. 6e) as compared to control littermates. Furthermore, the positive correlation between $P_{\mathrm{Osm}}$ and plasma AVP levels, as observed in Trpv $4^{+/+}$mice, was abolished in Trpv $4^{-1-}$ mice (Fig. 6f).

\section{Effect of TRPV4 disruption on peripheral osmoregulation}

The potential role of TRPV4 on the renal response to water deprivation was then investigated. Immunoblotting (whole kidney membrane fraction) showed similar membrane AQP2 and pS269 AQ2 levels in both genotypes at baseline and after water deprivation (Fig. 7a, b). The levels of p256 and p261 AQP2 were also found to be similar between Trpv4 ${ }^{-1-}$ mice and controls (Supplementary Material 1: Fig. 2). Immunostaining showed a similar increase in AQP2 signal intensity, membrane localization, and phosphorylation in the CDs of $\operatorname{Trp} v 4^{+/+}$and $\operatorname{Tr} v v 4^{-/-}$mice (Fig. 7c, d). Of note is that expression studies on whole kidney (real time (RT)-PCR) showed that Aqp2 mRNA expression levels, which were 
Fig. 4 Renal function testing in Trpv4 mice. a-e Effects of furosemide on $\operatorname{Trp} v 4^{+/+}$and $\operatorname{Trp} v 4^{-/}$mice. Furosemide injection induced an increase in diuresis (a) and a significant decrease in urine osmolality (b). Natriuresis (c), kaliuresis (d), and calciuresis (e) were increased as well. No difference was observed between $\operatorname{Tr} p v 4^{+/+}$and $\operatorname{Tr} p v 4^{-/}$ ( $n=5$ pairs). f, $\mathbf{g}$ Urinary $\mathrm{Na}^{+}$and $\mathrm{K}^{+}$excretion obtained with normal and $\mathrm{Na}^{+}$-depleted diets. At baseline (BL1 and BL2), mice were fed a diet containing $1 \%$ $\mathrm{NaCl}$. This baseline was followed by a $\mathrm{Na}^{+}$-depleted $\operatorname{diet}(0.01 \%$ $\mathrm{NaCl})$ for 17 days $(1-17)$. The amount of $\mathrm{Na}^{+}(\mathbf{f})$ and $\mathrm{K}^{+}(\mathrm{g})$ excreted in the urine of Trpv $4^{+/+}$ and $\operatorname{Trp} v 4^{-1-}$ mice was determined. Results are expressed as nanomoles of $\mathrm{Na}^{+}$and $\mathrm{K}^{+}$ excreted per nanogram of creatinine. No significant difference in $\mathrm{Na}^{+}$and $\mathrm{K}^{+}$ excretion was observed between $\operatorname{Tr} v 4^{+/+}$and $\operatorname{Tr} v v 4^{-/-}$mice at baseline and during sodium depletion ( $n=5$ pairs). $\mathbf{h}, \mathbf{i}$ Response to acid loading. Five pairs of mice were exposed to $\mathrm{NH}_{4} \mathrm{Cl}$ load for 0,2 , or 6 days. In $\operatorname{Trp} v 4^{+/+}$and Trpv $4^{-/-}$mice, the acid load reduced the urinary $\mathrm{pH}$ (h) and induced an increase in urinary excretion of ammonium (i). The two groups showed a similar response to this challenge. $* P<0.05$ vs. baseline

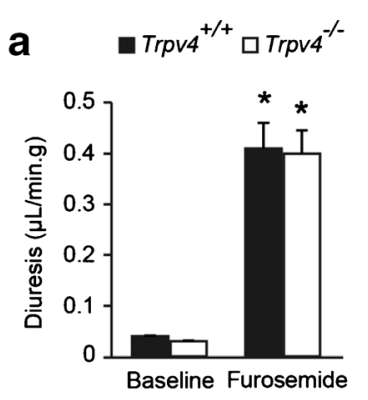

b

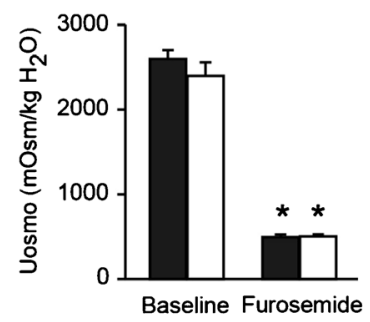

C

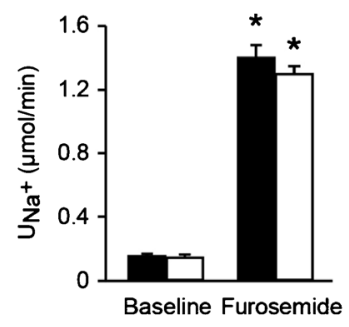

d e

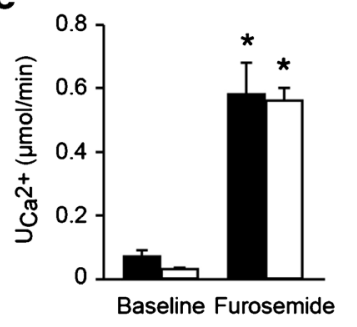

h
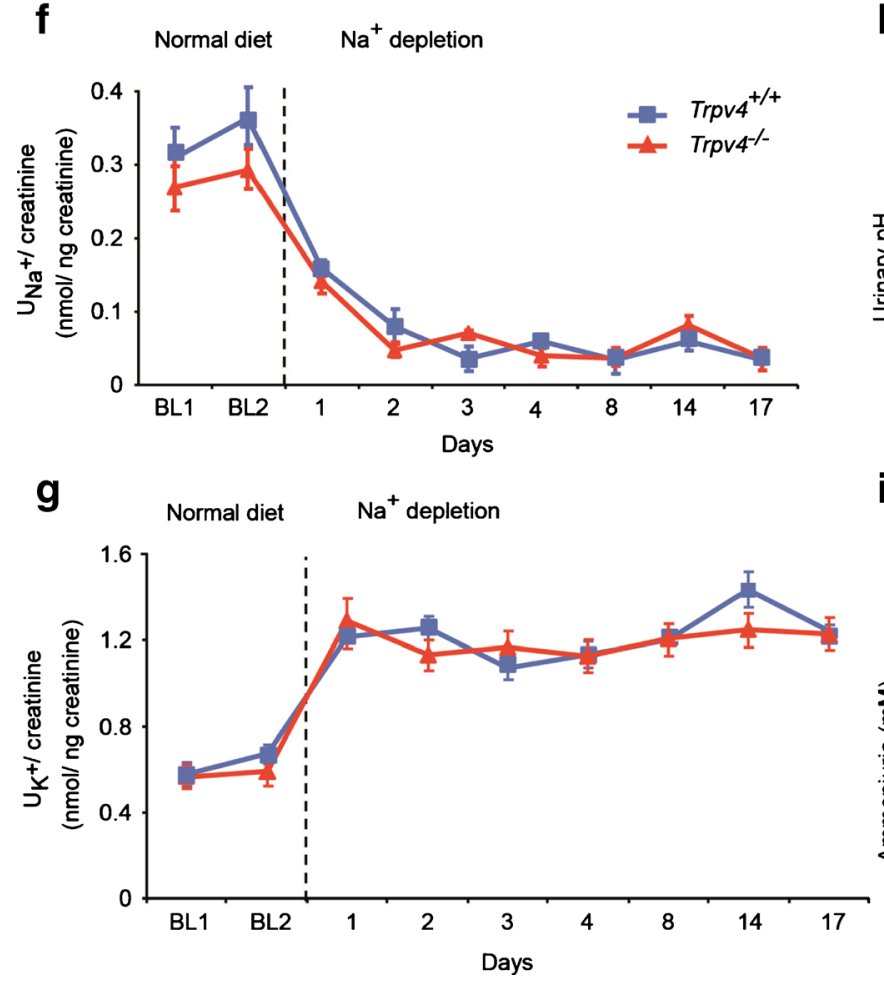

i
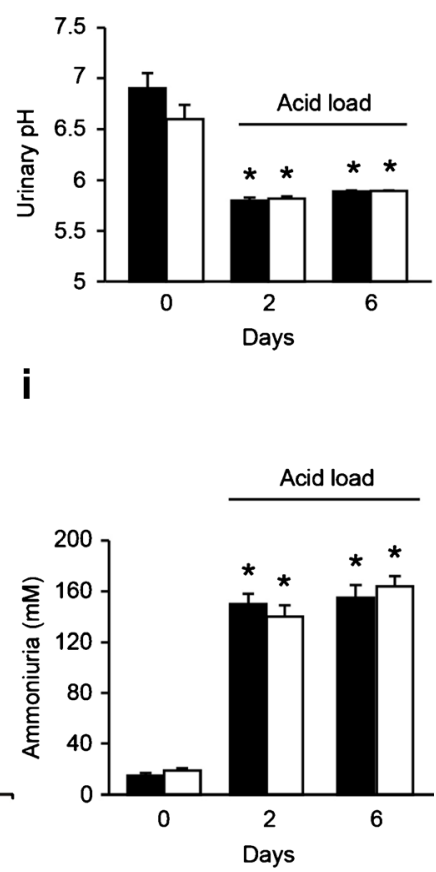

similar between both genotypes at baseline, showed a significantly lower rise after water deprivation in $\operatorname{Trp} v 4^{4^{-1}}$ mice. Expressions of Aqp3, AvpR1, and $A v p R 2$ were similarly regulated in both genotypes (Fig. 8a-d). Investigations of water handling were completed by injecting the V2R selective agonist dDAVP (1 ng/g; Fig. 9a). This treatment resulted in a similar increase in $U_{\text {Osm }}$ (after $5 \mathrm{~h}$ ) in both genotypes. In a reverse experiment, acute water loading $(100 \mu \mathrm{L} / \mathrm{g}$, IP) demonstrated that $\operatorname{Trp} v 4^{-/-}$and $\operatorname{Tr} p v 4^{+/+}$mice have a similar capacity to excrete water (Fig. 9b).
These results, and the lack of reactivity of plasma AVP under water deprivation, suggest the activation of a vasopressin-independent pathway to increase membrane AQP2 in Trpv $4^{-/}$mice $[4,6,25]$. In order to test whether the nitric oxide (NO) pathway could be involved, we compared the expression of nitric oxide synthases (NOS) in waterdeprived $\operatorname{Tr} v 4^{+/+}$and $\operatorname{Tr} v v 4^{-/-}$mice. There was a significant upregulation of NOS1 in Trpv $4^{-/-}$kidneys compared to controls, corresponding to enhanced NOS1 level in their inner medulla, with the highest signal in the vasculature 
Fig. 5 Hypertonic saline stimulation and water intake in Trpv 4 mice. After adaptation in Physiocage, mice were injected $0.5 \mathrm{M} \mathrm{NaCl}$ (IP) and monitored for subsequent water intake. As compared to wild-type

littermates, $\operatorname{Tr} v v 4^{-/-}$mice show a decreased cumulative water intake (a) (area under the curve: $\operatorname{Trp} v 4^{-1-}=953 \pm 159 \mathrm{~mL}$ vs. Trpv $4^{+/+}=1435 \pm 143 \mathrm{~mL}$; $P=0.04)$ and a significantly delayed water intake (b) $\left(T_{1 / 2}\right.$ $\mathrm{KO}=1056 \pm 245 \mathrm{~s}$ vs. $\mathrm{WT}=672$ $\pm 83 \mathrm{~s} ; P=0.03, n=10$ pairs).

$* P<0.05$ vs. control

Fig. 6 Effects of water deprivation on water balance in Trpv4 mice. Urine output (a) and urine osmolality (b) obtained at baseline $(B L)$ and after $24 \mathrm{~h}$ of water deprivation $(W D)$ show the same variations in both strains. In comparison with $\operatorname{Trpv} 4^{+/+}$ littermates, $\operatorname{Tr} p v 4^{-1-}$ mice exhibited a significantly higher rise in plasma osmolality (c), but a significantly lower upregulation of the levels of $A v p$ mRNA in the brain (d) and of the plasma levels of AVP $\left(P_{\mathrm{AVP}}\right)(\mathbf{e})$ after water deprivation. $\mathbf{f}$ Relationship between plasma osmolality $\left(P_{\mathrm{Osm}}\right)$ and vasopressin $\left(P_{\mathrm{AVP}}\right)$. After $24 \mathrm{~h}$ of water deprivation, in wild-type mice, the increase in $P_{\text {Osm }}$ was reflected by an important increase in $P_{\mathrm{AVP}}$ $\left(R^{2}=0.47\right)$. This relationship was lost in Trpv $4^{-/-}$mice $\left(R^{2}=0.04\right.$; $n=10$ pairs, except for (f) $n=20$ pairs). $* P<0.05$ vs. baseline; ${ }^{\#} P<0.05$ vs. controls

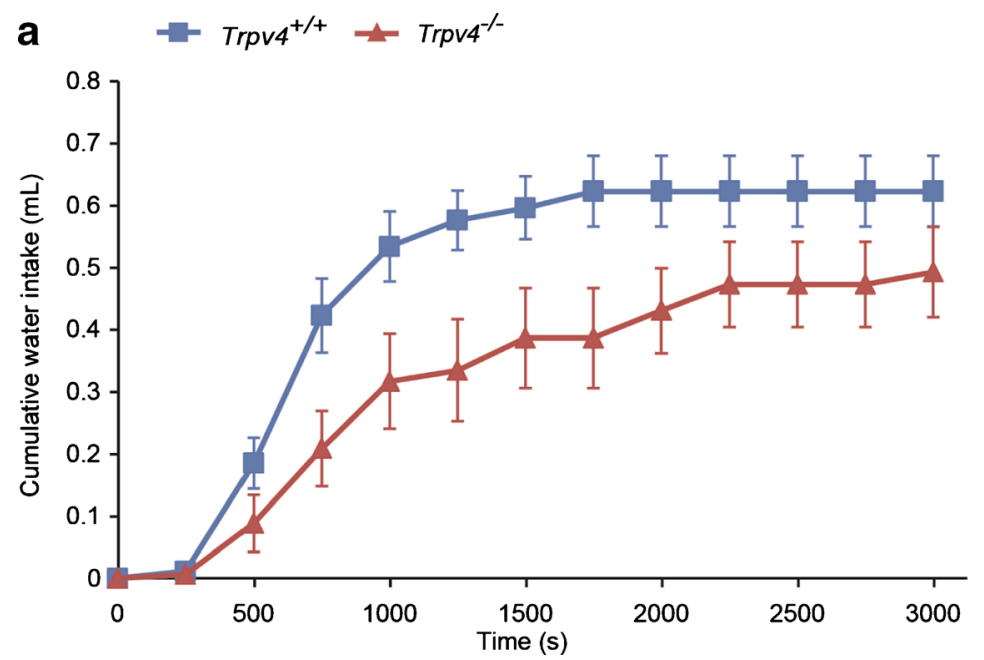

b

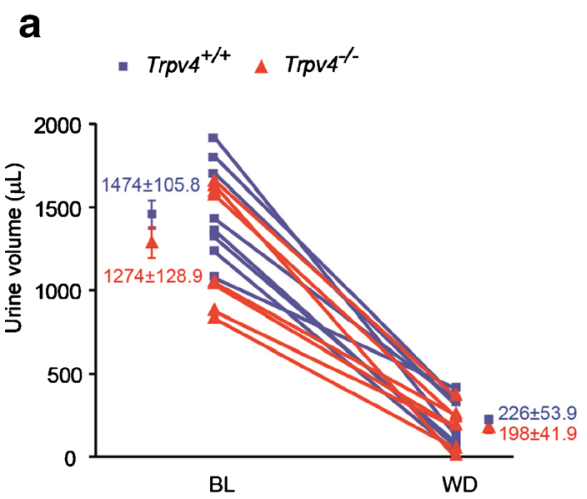

b
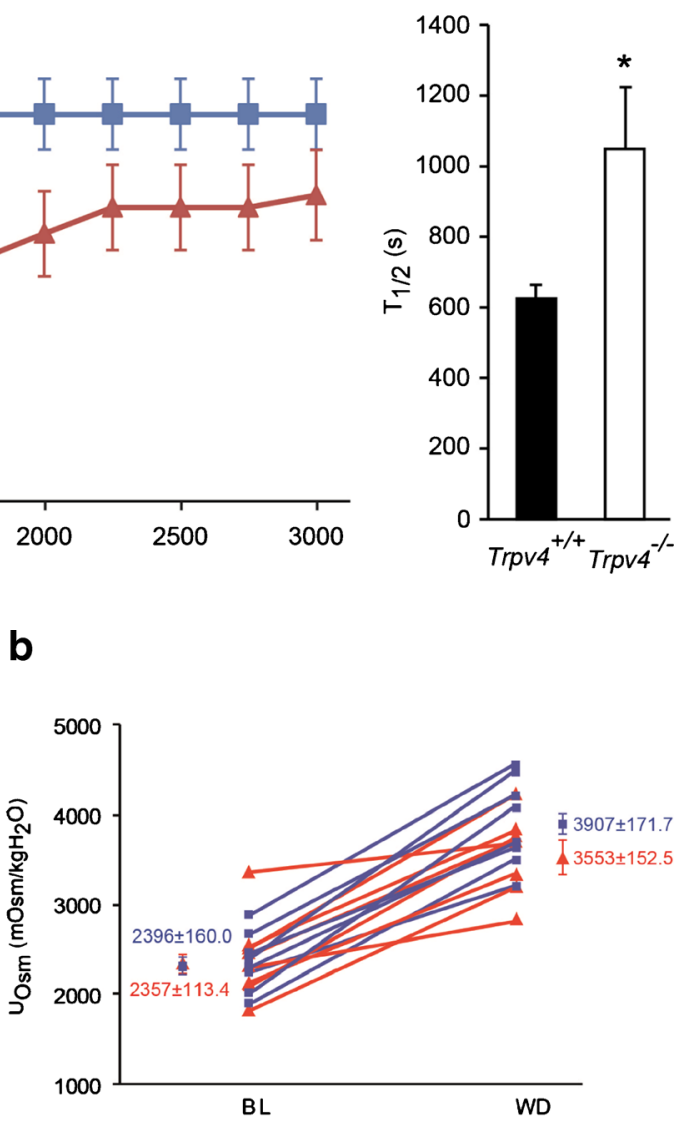

C

d

e
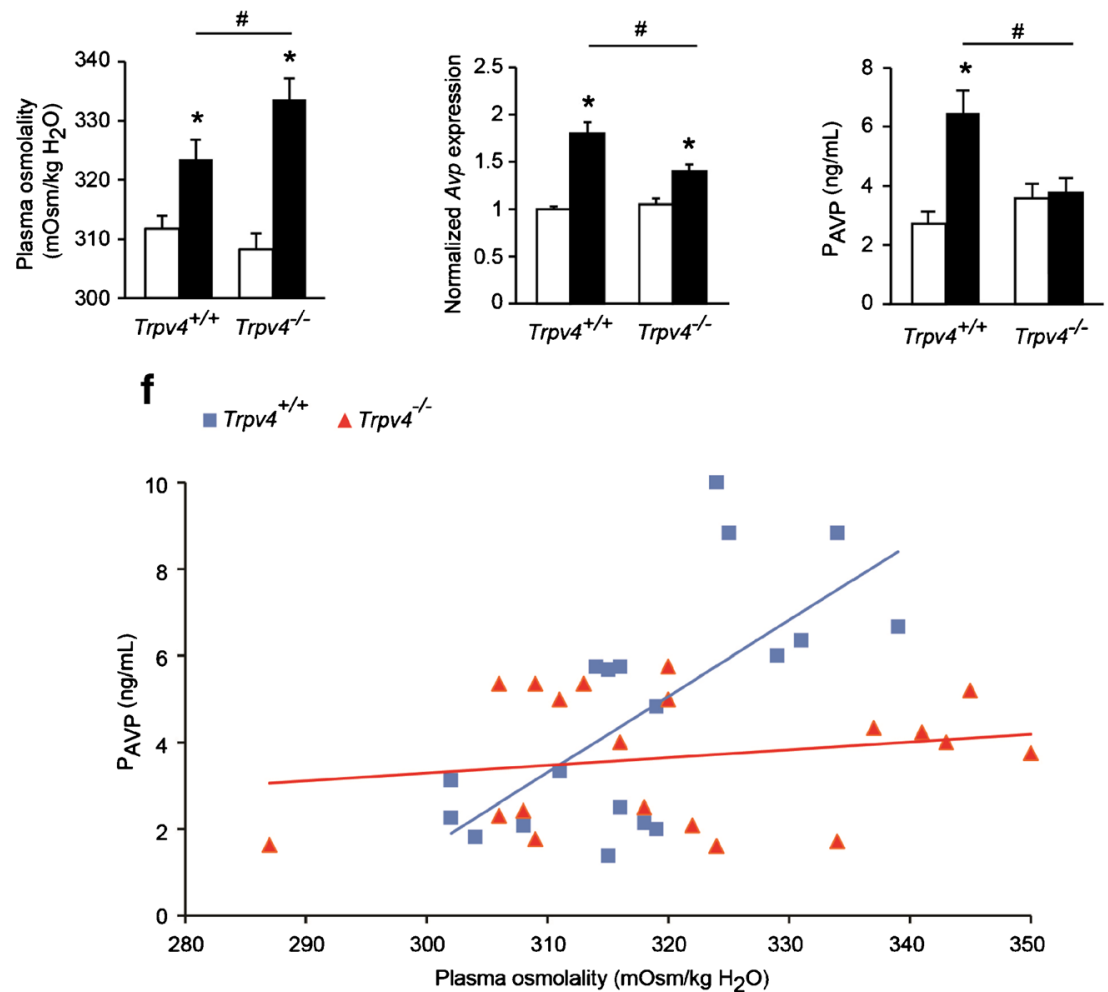
Fig. 7 Effects of water deprivation on AQP2 protein in Trp 4 kidneys. a Immunoblotting of pS269 (pAQP2) and total AQP2 comparing $\operatorname{Trp} v 4^{+/+}$and $\operatorname{Trp} v 4^{-/-}$kidneys at baseline $(B L)$ and after water deprivation $(W D)$. b, c Quantification of the immunobloting signals. Flotillin (FLOT) is used as a membrane fraction loading control. No difference was found at baseline or after water deprivation. $\mathbf{d}$ Immunoblotting of pS269 and total AQP2 analyzing the response to water deprivation within each genotype. $\mathbf{e}, \mathbf{f}$ Quantification of the immunobloting signals. Like controls, $\operatorname{Trp} v 4^{-/-}$kidneys showed a significant rise in AQP2 phosphorylation after water deprivation. $* P<0.05$ vs baseline. $\mathbf{g}, \mathbf{h}$ Immunostaining of AQP2 and pS269 AQP2 in CD under strictly controlled conditions showed a similar increase in signal and membrane localization in $\operatorname{Trp} v 4^{+/+}$and Trpv $4^{-1-} \mathrm{CD}$ after water deprivation. Scale bar, $50 \mathrm{~mm}$ a
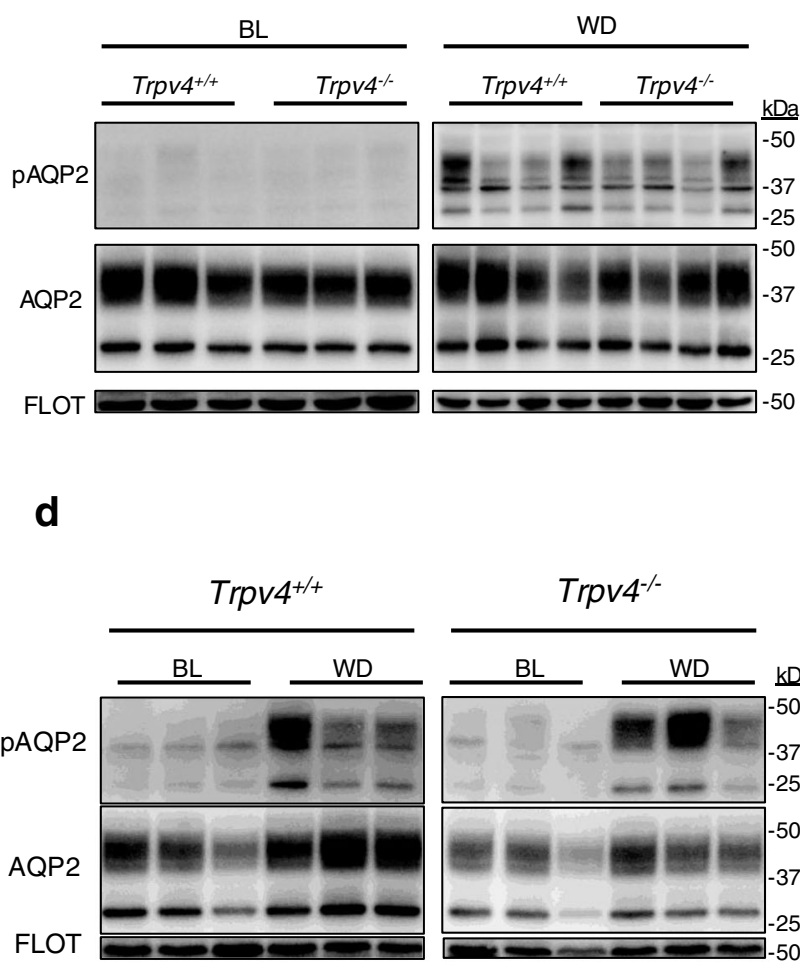

g
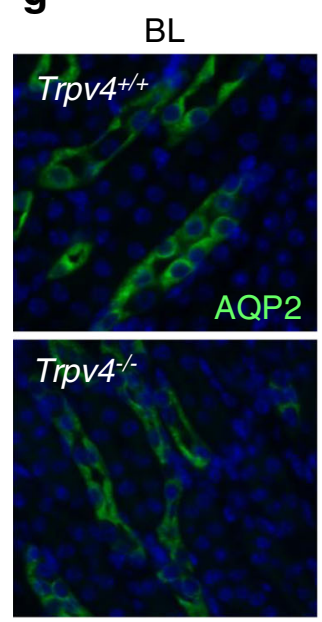

h
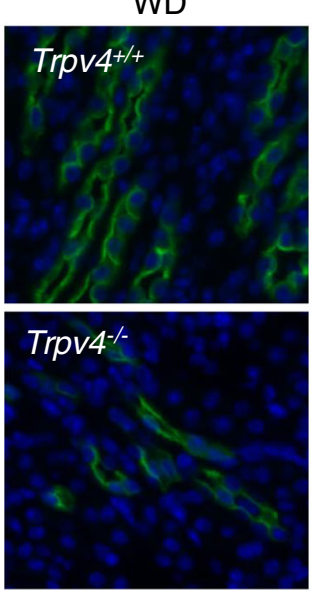
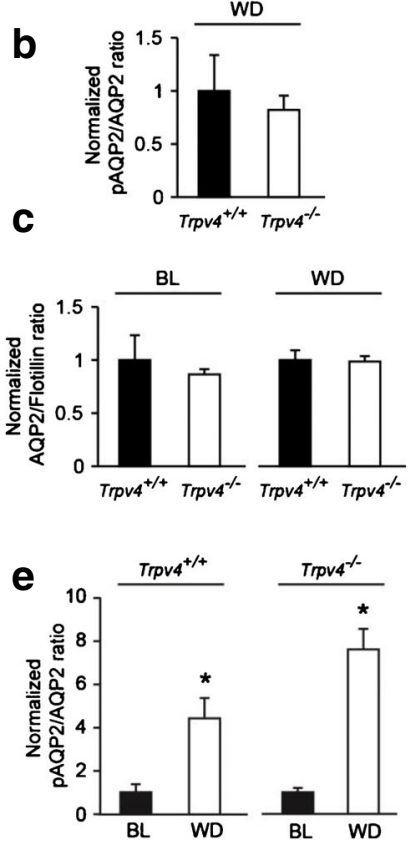

$f$
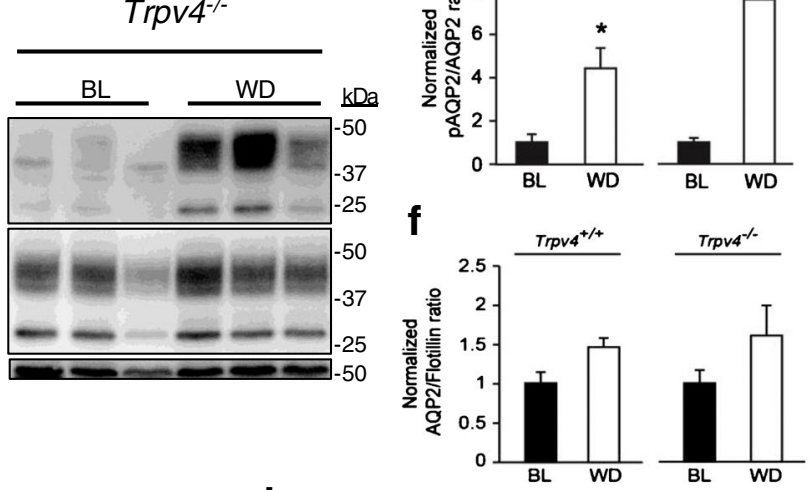

$\mathrm{BL}$
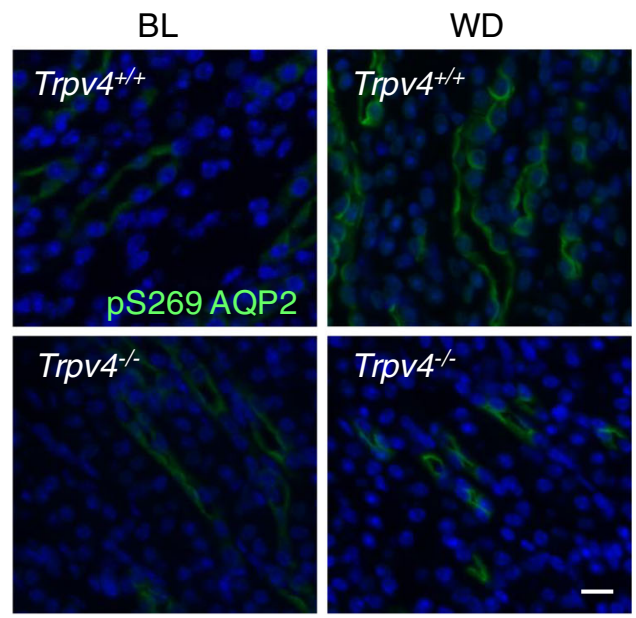

(Fig. 10a, b). Other isoforms were not upregulated (data not shown).

\section{Effect of TRPV4 activation on proximal tubule cells}

As TRPV4 was found to be highly expressed in the PT cells, which are characterized by a very efficient apical endocytosis, we further analyzed its role on the endocytic uptake of albumin in primary cultures of mPTCs [38]. We first verified that we could activate TRPV4 in MPTCs with the specific agonist
GSK1016790A: stimulation of Trpv4 ${ }^{+/+}$mPTC with $100 \mathrm{nM}$ GSK1016790A induced a large increase in $\left[\mathrm{Ca}^{2+}\right]_{\mathrm{i}}$, which was not observed in Trpv $4^{-1-}$ mPTC (Fig. 11a). Then, we compared endocytosis of FITC-labeled albumin [38] between $\operatorname{Tr} v v 4^{+/+}$and Trpv $4^{-1}$ mPTCs (Fig. 11b). In standard conditions, the endocytosis of FITC-labeled albumin was similar between the two genotypes. However, activation of TRPV4 with GSK1016790A enhanced albumin endocytosis in Trpv $4^{+/+}$mPTC. This effect was not observed in $\operatorname{Trp} v 4^{-1-}$ mPTC. 
a
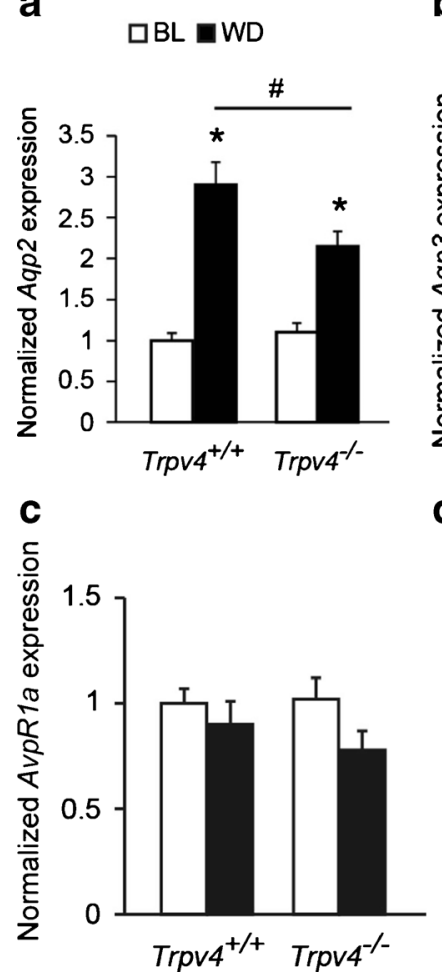

genetic deletion of TRPV4 on the central and nephrogenic components of osmoregulation. In contrast to previous studies, we demonstrate that TRPV4 is absent from the TAL, but abundantly expressed in proximal and distal tubular segments. Despite the widespread expression pattern of TRPV4 in the kidney, its deletion has no detectable effect on a large range of renal function parameters. Conversely, the absence of TRPV4 is associated with abnormal thirst regulation and vasopressin release, demonstrating a key role in central osmoregulation.

Knockout (KO) mice for TRPV4 express a relatively subtle phenotype [17, 21, 24]. Indeed, Mizuno et al. reported no perturbation under normal conditions, but an exaggerated secretion of AVP in response to hyperosmolarity. Using another line, Liedtke et al. reported that $\operatorname{Trpv} 4^{-/-}$mice drank less and were slightly hyperosmolar. AVP secretion in response to hyperosmotic stimulation was diminished, with lower fluid intake and increased latency of drinking. In a third study, Kinsman et al. found no difference in water intake following hyperosmotic challenge between this latter model and controls. Besides these KO models, other studies linked TRPV4 to AVP secretion in SON [11], modulated thirst with a TRPV4 agonist [41], or showed its role in osmosensitivity of the PVN $[13,14]$. TRPV4 has also been described as a peripheral osmoreceptor in nerve endings surrounding hepatic blood vessels [19]. However, the fact that human patients with denervated liver (liver-transplanted patients) have an elevated plasma osmolality in combination with elevated levels of the Cterminal pro-AVP suggests an appropriate central response in the absence of this peripheral osmoreceptor.

Our studies, based on the Trpv $4^{--}$mouse model developed by Liedtke et al. which was backcrossed on an inbred C57BL/ 6 background, reveal a significantly impaired ability of Trpv 4 KO mice to increase AVP expression and secretion upon water deprivation. Furthermore, $\operatorname{Trp} v 4^{-1-}$ mice had a significantly

In this study, we detailed the expression profile of TRPV4 in mouse kidney and analyzed the consequences of the

a

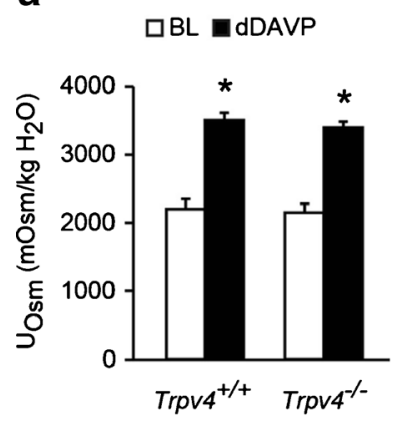

b

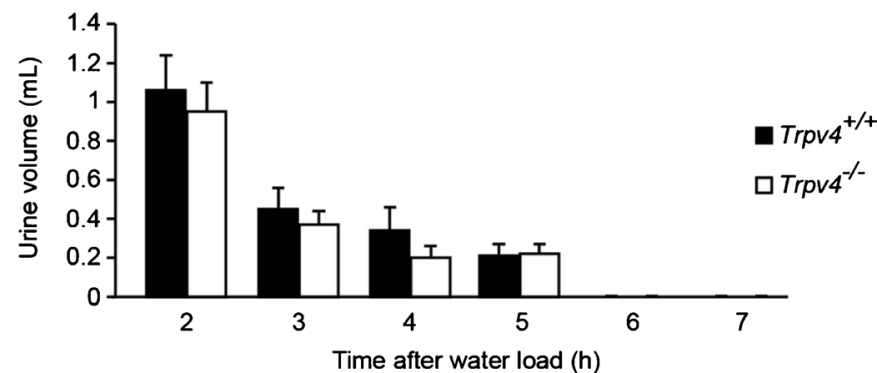

Fig. 9 Investigations on water handling by the Trpv 4 kidney. a Effect of dDAVP treatment on urine osmolarity in $\operatorname{Trp} v 4^{+/+}$and $\operatorname{Trp} v 4^{-/-}$mice. Urine osmolality $\left(U_{\mathrm{Osm}}\right)$ was measured at baseline and $5 \mathrm{~h}$ after injection of $1 \mathrm{ng} / \mathrm{g}$ dDAVP (Minirin ${ }^{\circledR}, \mathrm{IP}$ ). The two groups of mice showed similar $U_{\text {Osm }}$ values at baseline $(2238 \pm 175$ vs. 2245 $\pm 144 \mathrm{mOsm} / \mathrm{kg} \mathrm{H} \mathrm{H}_{2} \mathrm{O}$ ). dDAVP injection induced an increase of $U_{\mathrm{Osm}}$; however, no significant difference was observed between $\operatorname{Trp} v 4^{-/-}$mice and wild-type littermates ( $3371 \pm 78$ vs. $3534 \pm 110 \mathrm{mOsm} / \mathrm{kg} \mathrm{H}_{2} \mathrm{O} ; n=6$ pairs of mice). ${ }^{*} P<0.05$ vs. baseline. $\mathbf{b}$ Response to water loading in $\operatorname{Trp} v 4^{+/+}$and $\operatorname{Trp} v 4^{-/-}$mice. Ten pairs of mice were administered an IP injection of water $(100 \mu \mathrm{L} / \mathrm{g})$ and urine volume (in milliliters) was measured every hour. Each group showed the same ability to excrete water after injection 
a

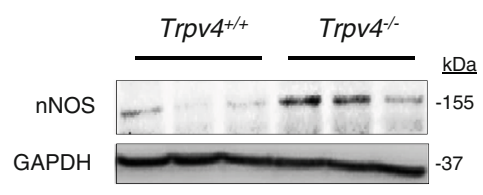

b
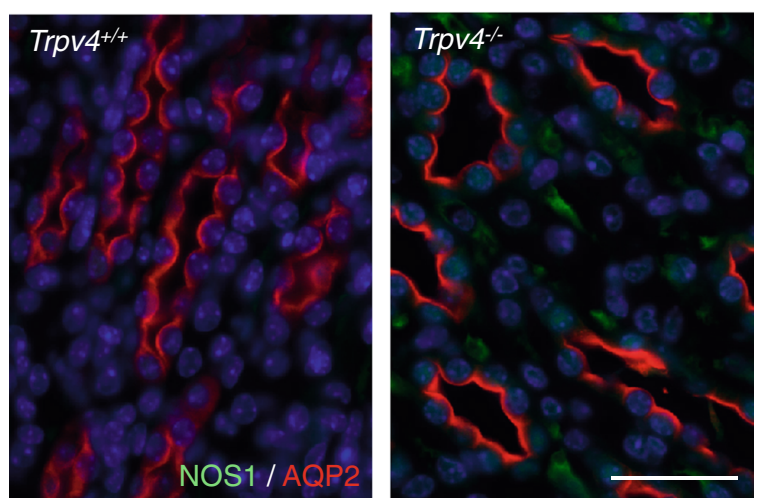

Fig. 10 Effects of water deprivation on NOS1 expression in Trpv4 kidneys. a Immunoblotting of NOS1 conducted on whole kidney extracts. Comparison of NOS1 levels in $\operatorname{Trp} v 4^{+/+}$and $\operatorname{Trp} v 4^{-/-}$kidneys after water deprivation revealed a significantly higher level in $\operatorname{Tr} p v 4^{-1-}$ mice. GAPDH is used as a loading control. ${ }^{*} P<0.05$ vs. controls. b Immunostaining on kidneys from water-deprived mice showed a higher NOS1 level in Trpv $4^{-/-}$inner medulla, particularly in the vessels, in comparison with the controls. AQP2 is used to stain principal cells of the CD. Scale bar, $50 \mu \mathrm{m}$

higher plasma osmolality and a reduced Aqp2 mRNA upregulation after 24-h water deprivation. The latter findings are probably related to defective AVP secretion, as also evidenced

a

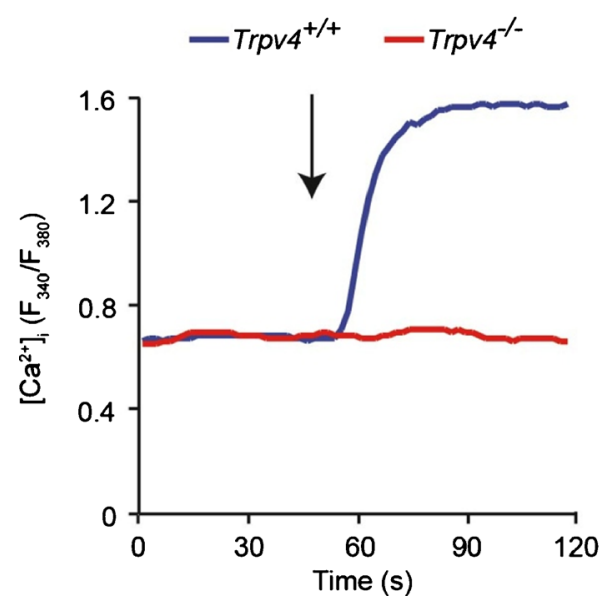

Fig. 11 Role of TRPV4 on albumin endocytosis in mPTC. a Expression of a functional TRPV4 channel in the MPTC was verified by monitoring $\left[\mathrm{Ca}^{2+}\right]_{\mathrm{i}}$ in the presence of the TRPV4 agonist GSK1016790A (100 nM, arrow). Specificity of the agonist was verified on $\operatorname{Trp} v 4^{-1-} \mathrm{mPTC}$. The graph represents the average response of ten cells for each condition and is representative of five different experiments. b $\operatorname{Tr} p v 4^{+/+}$and $\operatorname{Tr} p v 4^{-/-}$ by the loss of the typical positive correlation between plasma osmolality and plasma AVP levels. This correlation was also lost in Trpv1 $1^{-/-}$mice (Fig. 6 from this article can be paralleled to Fig. 6 from [35]), indicating that TRPV1 and TRPV4 are both needed in the mechanism of AVP secretion. These findings indicate that the loss of TRPV4 alters the function of central osmoreceptors implicated in the regulation of AVP secretion. The central defect is also reflected by an alteration of the mechanism of thirst, as evidenced by the significant delay in the water intake in $\operatorname{Tr} p v 4^{-1-}$ mice after hypertonic saline injection.

The distribution and physiological role of TRPV4 in the kidney remain debated $[23,32]$. Our studies, based on RTqPCR, immunostaining, and gene expression reporting in mouse kidney, show consistently that TRPV4 is abundantly expressed in the apical and basolateral areas of PT cells and essentially at the basolateral membrane of the late DCT, the $\mathrm{CN}$, and the $\mathrm{CD}$, including principal and intercalated cells. In contrast, TRPV4 is absent from the glomerulus and the TAL. This pattern of distribution differs from that published in two previous reports $[2,40]$. Immunostaining for TRPV4 on rat and mouse kidneys performed by Tian et al. suggests that it is expressed in the basolateral membrane of the TAL and the downstream nephron segments, but was not validated on a KO model. On the other hand, Berrout et al. showed expression (predominantly apical) from the $\mathrm{CN}$ through the papillary $\mathrm{CD}$. While the antibody properties and the immunostaining conditions could explain the absence of positive PT staining in the latter study, our pattern is strongly supported by nonimmunological evidences that are RNA expression and lacZ reporting studies.

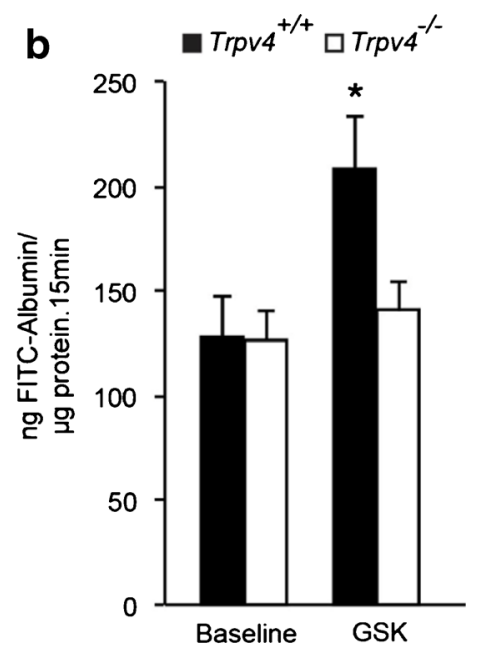

mPTCs were exposed to $0.5 \mathrm{mg} / \mathrm{mL}$ FITC-labeled albumin for $15 \mathrm{~min}$ and the uptake was quantified. No significant difference was found at baseline, but in the presence of $100 \mathrm{nM}$ GSK1016790A (GSK), albumin uptake was enhanced in $\operatorname{Trp} v 4^{+/+} \mathrm{mPTC}$ but not in $\operatorname{Trp} v 4^{-/-}$ mPTC ( $n=9$ filters from three different mice for each condition). $* P<0.05$ vs. Trpv $4^{+/+}$baseline 
Several lines of evidence were used to assess the potential role(s) of TRPV4 in these nephron segments. Studies performed at baseline failed to show any difference in behavior and plasma and urine parameters between $\operatorname{Trp} v 4^{-/-}$and $\operatorname{Trp} v 4^{+/+}$mice. An extensive set of functional tests was also used, failing to show significant differences in the renal response between $\operatorname{Trp} v 4^{-/-}$and $\operatorname{Tr} v v 4^{+/+}$mice: furosemide treatment, $\mathrm{NaCl}$ depletion, acid loading, water deprivation, dDAVP treatment, and water loading. These negative results have to be interpreted in view of in vitro studies that have demonstrated a physiological role of TRPV4 as a flow sensor on mouse renal epithelial cell line [44] and isolated CD [2, 3, 37]. Although there was no biological sign of PT dysfunction in $\operatorname{Trp} v 4^{-/-}$mice at baseline, we show that TRPV4 activation can enhance endocytosis in mPTC. Further investigations will be needed to evaluate the potential role of TRPV4 in the mecanosensors regulating the PT functions [33, 34]. The fact that the kidney is a site of high TRPV4 expression compared to other organs $[18,20]$, with TRPV4 being one of the most expressed TRP channels [18], may suggest that redundant mechanisms compensate for the lack of TRPV4 in $\operatorname{Trp} v 4^{-/-}$kidneys. Despite the defect in AVP secretion, the renal response to 24-h water deprivation was found to be functional in $\operatorname{Trp} v 4^{-/-}$mice as the urine concentrating ability and AQP2 trafficking and phosphorylation were not significantly different between $\operatorname{Tr} p v 4^{-/-}$mice and controls. Interestingly, we found an upregulation of NOS1 in the inner medulla of water-deprived $\operatorname{Tr} p v 4^{-/-}$mice, where NO signaling could be an alternative pathway to increase membrane AQP2 in the absence of AVPR2 stimulation [4, 5].

In conclusion, despite abundant TRPV4 expression in the proximal and distal nephron segments, the Trpv $4^{-1-}$ mouse does not highlight a major renal dysfunction at baseline. Instead, TRPV4 is critical for the release of vasopressin, the thirst sensation and the central regulation of osmolality.

Acknowledgments These studies were supported by the Belgian agencies 'Fonds National de la Recherche Scientifique' (FNRS), 'Fonds de la Recherche Scientifique Médicale' (FRSM), and 'Association belge contre les maladies neuro-musculaires' (ABMM), the concerted Research Action (10/15-029), the Interuniversity Poles of Attraction Belgian Science Policy (P7/13), the European Community's Seventh Framework Programme (FP7/2007-2013) under grant agreement no. 305608 (EURenOmics), the "Association française contre les myopathies" (AFM grant 16738), the Swiss National Science Foundation project grant 310030_146490; the KFSP RADIZ (Rare Disease Initiative Zurich), and MINZ (Molecular Imaging Network Zurich) from the University of Zurich. We are grateful to Drs. M. A. Knepper (Bethesda) and C. A. Wagner (Zurich) for help and advice and to H. Debaix, Y. Cnops, S. Druart, N. Amraoui, and X. Yerna for excellent technical assistance. F. Seghers is a Research Fellow of the FNRS.

\section{Compliance with ethical standards}

Conflict of interest The authors declare that that they have no conflicts of interest.
Research involving animals All applicable international, national, and/or institutional guidelines for the care and use of animals were followed. All procedures performed in studies involving animals were in accordance with the ethical standards of the institution or practice at which the studies were conducted.

\section{References}

1. Ahrabi AK, Terryn S, Valenti G, Caron N, Serradeil-Le Gal C, Raufaste D, Nielsen S, Horie S, Verbavatz JM, Devuyst O (2007) PKD1 haploinsufficiency causes a syndrome of inappropriate antidiuresis in mice. J Am Soc Nephrol 18:1740-1753. doi:10.1681/ASN.2006010052

2. Berrout J, Jin M, Mamenko M, Zaika O, Pochynyuk O, O’Neil RG (2012) Function of transient receptor potential cation channel subfamily V member 4 (TRPV4) as a mechanical transducer in flow-sensitive segments of renal collecting duct system. J Biol Chem 287:8782-8791. doi:10.1074/jbc.M111.308411

3. Berrout J, Mamenko M, Zaika OL, Chen L, Zang W, Pochynyuk O, O'Neil RG (2014) Emerging role of the calcium-activated, small conductance, $\mathrm{SK} 3 \mathrm{~K}^{+}$channel in distal tubule function: regulation by TRPV4. PLoS One 9:e95149. doi:10.1371/journal. pone.0095149

4. Bouley R, Breton S, Sun T, McLaughlin M, Nsumu NN, Lin HY, Ausiello DA, Brown D (2000) Nitric oxide and atrial natriuretic factor stimulate cGMP-dependent membrane insertion of aquaporin 2 in renal epithelial cells. J Clin Invest 106:1115-1126. doi:10.1172 /JCI9594

5. Bouley R, Hasler U, Lu HA, Nunes P, Brown D (2008) Bypassing vasopressin receptor signaling pathways in nephrogenic diabetes insipidus. Semin Nephrol 28:266-278. doi:10.1016/j. semnephrol.2008.03.010

6. Bouley R, Pastor-Soler N, Cohen O, McLaughlin M, Breton S, Brown D (2005) Stimulation of AQP2 membrane insertion in renal epithelial cells in vitro and in vivo by the cGMP phosphodiesterase inhibitor sildenafil citrate (Viagra). Am J Physiol Renal Physiol 288:F1103-F1112. doi:10.1152/ajprenal.00337.2004

7. Bourque CW (2008) Central mechanisms of osmosensation and systemic osmoregulation. Nat Rev Neurosci 9:519-531. doi:10.1038/nrn2400

8. Bourque CW, Ciura S, Trudel E, Stachniak TJ, Sharif-Naeini R (2007) Neurophysiological characterization of mammalian osmosensitive neurones. Exp Physiol 92:499-505. doi:10.1113 /expphysiol.2006.035634

9. Bourque CW, Oliet SH, Richard D (1994) Osmoreceptors, osmoreception, and osmoregulation. Front Neuroendocrinol 15: 231-274. doi:10.1006/frne.1994.1010

10. Buggy J, Jonhson AK (1977) Preoptic-hypothalamic periventricular lesions: thirst deficits and hypernatremia. Am J Physiol 233:R44-R52

11. Carreno FR, Ji LL, Cunningham JT (2009) Altered central TRPV4 expression and lipid raft association related to inappropriate vasopressin secretion in cirrhotic rats. Am J Physiol Regul Integr Comp Physiol 296:R454-R466. doi:10.1152/ajpregu.90460.2008

12. Ciura S, Liedtke W, Bourque CW (2011) Hypertonicity sensing in organum vasculosum lamina terminalis neurons: a mechanical process involving TRPV1 but not TRPV4. J Neurosci 31:1466914676. doi:10.1523/JNEUROSCI.1420-11.2011

13. Feetham CH, Nunn N, Barrett-Jolley R (2015) The depressor response to intracerebroventricular hypotonic saline is sensitive to TRPV4 antagonist RN1734. Front Pharmacol 6:83. doi:10.3389 /fphar.2015.00083 
14. Feetham CH, Nunn N, Lewis R, Dart C, Barrett-Jolley R (2015) TRPV4 and $\mathrm{K}(\mathrm{Ca})$ ion channels functionally couple as osmosensors in the paraventricular nucleus. Br J Pharmacol 172: 1753-1768. doi:10.1111/bph.13023

15. Gu Y, Gu C (2014) Physiological and pathological functions of mechanosensitive ion channels. Mol Neurobiol 50:339-347. doi:10.1007/s12035-014-8654-4

16. Jouret F, Auzanneau C, Debaix H, Wada GH, Pretto C, Marbaix E, Karet FE, Courtoy PJ, Devuyst O (2005) Ubiquitous and kidneyspecific subunits of vacuolar $\mathrm{H}^{+}$-ATPase are differentially expressed during nephrogenesis. J Am Soc Nephrol 16:32353246. doi:10.1681/ASN.2004110935

17. Kinsman B, Cowles J, Lay J, Simmonds SS, Browning KN, Stocker SD (2014) Osmoregulatory thirst in mice lacking the transient receptor potential vanilloid type 1 (TRPV1) and/or type 4 (TRPV4) receptor. Am J Physiol Regul Integr Comp Physiol 307:R1092-R1100. doi:10.1152/ajpregu.00102.2014

18. Kunert-Keil C, Bisping F, Kruger J, Brinkmeier H (2006) Tissuespecific expression of TRP channel genes in the mouse and its variation in three different mouse strains. BMC Genomics 7:159. doi:10.1186/1471-2164-7-159

19. Lechner SG, Markworth S, Poole K, Smith ES, Lapatsina L, Frahm S, May M, Pischke S, Suzuki M, Ibanez-Tallon I, Luft FC, Jordan J, Lewin GR (2011) The molecular and cellular identity of peripheral osmoreceptors. Neuron 69:332-344. doi:10.1016/j. neuron.2010.12.028

20. Liedtke W, Choe Y, Marti-Renom MA, Bell AM, Denis CS, Sali A, Hudspeth AJ, Friedman JM, Heller S (2000) Vanilloid receptorrelated osmotically activated channel (VR-OAC), a candidate vertebrate osmoreceptor. Cell 103:525-535

21. Liedtke W, Friedman JM (2003) Abnormal osmotic regulation in trpv $4^{-1-}$ mice. Proc Natl Acad Sci U S A 100:13698-13703. doi:10.1073/pnas.1735416100

22. Liedtke W, Tobin DM, Bargmann CI, Friedman JM (2003) Mammalian TRPV4 (VR-OAC) directs behavioral responses to osmotic and mechanical stimuli in Caenorhabditis elegans. Proc Natl Acad Sci U S A 100(Suppl 2):14531-14536. doi:10.1073 /pnas.2235619100

23. Mamenko M, Zaika O, Boukelmoune N, O’Neil RG, Pochynyuk O (2014) Deciphering physiological role of the mechanosensitive TRPV4 channel in the distal nephron. Am J Physiol Renal Physiol:ajprenal 00485:02014. doi:10.1152/ajprenal.00485.2014

24. Mizuno A, Matsumoto N, Imai M, Suzuki M (2003) Impaired osmotic sensation in mice lacking TRPV4. Am J Physiol Cell Physiol 285:C96-C101. doi:10.1152/ajpcell.00559.2002

25. Morishita T, Tsutsui M, Shimokawa H, Sabanai K, Tasaki H, Suda O, Nakata S, Tanimoto A, Wang KY, Ueta Y, Sasaguri Y, Nakashima Y, Yanagihara N (2005) Nephrogenic diabetes insipidus in mice lacking all nitric oxide synthase isoforms. Proc Natl Acad Sci U S A 102:10616-10621. doi:10.1073/pnas.0502236102

26. Nilius B, Honore E (2012) Sensing pressure with ion channels. Trends Neurosci 35:477-486. doi:10.1016/j.tins.2012.04.002

27. Nilius B, Vriens J, Prenen J, Droogmans G, Voets T (2004) TRPV4 calcium entry channel: a paradigm for gating diversity. Am J Physiol Cell Physiol 286:C195-C205. doi:10.1152/ajpcell.00365.2003

28. Oliet SH, Bourque CW (1992) Properties of supraoptic magnocellular neurones isolated from the adult rat. J Physiol 455:291-306

29. Oliet SH, Bourque CW (1993) Mechanosensitive channels transduce osmosensitivity in supraoptic neurons. Nature 364:341-343. doi: $10.1038 / 364341 \mathrm{a} 0$

30. Pearce D, Soundararajan R, Trimpert C, Kashlan OB, Deen PM, Kohan DE (2015) Collecting duct principal cell transport processes and their regulation. Clin J Am Soc Nephrol 10:135-146. doi:10.2215/CJN.05760513

31. Pernot E, Terryn S, Cheong SC, Markadieu N, Janas S, Blockmans M, Jacoby M, Pouillon V, Gayral S, Rossier BC, Beauwens R, Erneux C, Devuyst O, Schurmans S (2011) The inositol Inpp5k 5-phosphatase affects osmoregulation through the vasopressinaquaporin 2 pathway in the collecting system. Pflugers Arch 462:871-883. doi:10.1007/s00424-011-1028-0

32. Pochynyuk O, Zaika O, O'Neil RG, Mamenko M (2013) Novel insights into TRPV4 function in the kidney. Pflugers Arch 465: 177-186. doi:10.1007/s00424-012-1190-Z

33. Raghavan V, Rbaibi Y, Pastor-Soler NM, Carattino MD, Weisz OA (2014) Shear stress-dependent regulation of apical endocytosis in renal proximal tubule cells mediated by primary cilia. Proc Natl Acad Sci U S A 111:8506-8511. doi:10.1073/pnas.1402195111

34. Raghavan V, Weisz OA (2016) Discerning the role of mechanosensors in regulating proximal tubule function. Am $\mathrm{J}$ Physiol Renal Physiol 310:F1-F5. doi:10.1152 /ajprenal.00373.2015

35. Sharif Naeini R, Witty MF, Seguela P, Bourque CW (2006) An N-terminal variant of Trpv1 channel is required for osmosensory transduction. Nat Neurosci 9:93-98. doi:10.1038/nn1614

36. Strotmann R, Harteneck C, Nunnenmacher K, Schultz G, Plant TD (2000) OTRPC4, a nonselective cation channel that confers sensitivity to extracellular osmolarity. Nat Cell Biol 2:695-702. doi: $10.1038 / 35036318$

37. Taniguchi J, Tsuruoka S, Mizuno A, Sato J, Fujimura A, Suzuki M (2007) TRPV4 as a flow sensor in flow-dependent $\mathrm{K}^{+}$secretion from the cortical collecting duct. Am J Physiol Renal Physiol 292:F667-F673. doi:10.1152/ajprenal.00458.2005

38. Terryn S, Jouret F, Vandenabeele F, Smolders I, Moreels M, Devuyst O, Steels P, Van Kerkhove E (2007) A primary culture of mouse proximal tubular cells, established on collagen-coated membranes. Am J Physiol Renal Physiol 293:F476-F485. doi:10.1152/ajprenal.00363.2006

39. Tian W, Fu Y, Garcia-Elias A, Fernandez-Fernandez JM, Vicente R, Kramer PL, Klein RF, Hitzemann R, Orwoll ES, Wilmot B, McWeeney S, Valverde MA, Cohen DM (2009) A loss-offunction nonsynonymous polymorphism in the osmoregulatory TRPV4 gene is associated with human hyponatremia. Proc Natl Acad Sci U S A 106:14034-14039. doi:10.1073/pnas.0904084106

40. Tian W, Salanova M, Xu H, Lindsley JN, Oyama TT, Anderson S, Bachmann S, Cohen DM (2004) Renal expression of osmotically responsive cation channel TRPV4 is restricted to water-impermeant nephron segments. Am J Physiol Renal Physiol 287:F17-F24. doi:10.1152/ajprenal.00397.2003

41. Tsushima H, Mori M (2006) Antidipsogenic effects of a TRPV4 agonist, 4alpha-phorbol 12,13-didecanoate, injected into the cerebroventricle. Am J Physiol Regul Integr Comp Physiol 290: R1736-R1741. doi:10.1152/ajpregu.00043.2005

42. Vriens J, Watanabe H, Janssens A, Droogmans G, Voets T, Nilius B (2004) Cell swelling, heat, and chemical agonists use distinct pathways for the activation of the cation channel TRPV4. Proc Natl Acad Sci U S A 101:396-401. doi:10.1073/pnas.0303329101

43. Watanabe H, Vriens J, Prenen J, Droogmans G, Voets T, Nilius B (2003) Anandamide and arachidonic acid use epoxyeicosatrienoic acids to activate TRPV4 channels. Nature 424:434-438. doi:10.1038/nature01807

44. Wu L, Gao X, Brown RC, Heller S, O’Neil RG (2007) Dual role of the TRPV4 channel as a sensor of flow and osmolality in renal epithelial cells. Am J Physiol Renal Physiol 293:F1699-F1713. doi:10.1152/ajprenal.00462.2006 